Paidéia, 2001, 11(20), 29-38

\title{
PENSAMENTO, LINGUAGEM E CONSCIÊNCIA NOS TEXTOS INICIAIS DE FREUD ${ }^{1}$
}

\author{
Fátima Caropreso ${ }^{2}$ \\ Universidade Federal de São Carlos
}

\begin{abstract}
RESUMO: O objetivo deste artigo é mostrar a relação estabelecida por Freud entre o pensamento a linguagem e a consciência nos textos: "Sobre a concepção das afasias", (Freud, 1891/1973), e "Projeto de uma psicologia", (Freud, 1895/1950). O conceito de "representação de palavra", proposto por Freud no primeiro texto, é retomado, no segundo, para explicar como é possível a rememoração consciente do pensamento. No Projeto..., Freud propõe que a consciência, inicialmente, é apenas imediata e perceptiva e que o surgimento de uma consciência mediata do pensamento depende da constituição das associações lingüísticas, ou seja, da representação de palavra. Portanto, a linguagem possibilita a rememoração e, como conseqüência disto, permite o raciocínio e o conhecimento real dos objetos. Esse vínculo estabelecido por Freud entre a linguagem e a consciência nesses dois textos iniciais é mantido ao longo de toda a sua obra.
\end{abstract}

Palavras Chave: Psicanálise; Freud; Representação; Linguagem; Pensamento; Consciência.

\section{THOUGHT, LANGUAGE AND CONSCIOUSNESS IN FREUD'S EARLY WORKS}

\begin{abstract}
The aim of this paper is to present the relationship proposed by Freud between thought, language and consciousness in his "On the concept of aphasia" of (Freud, 1891/1973) and "Project for a psychology", (Freud, 1895/1950). The concept of "word representation" introduced by Freud in the first text is taken up in the second in order to explain how conscious recollection of thought is possible. For Freud, consciousness is at first only immediate perception and the appearance of a mediate consciousness of thought depends on the forming of linguistic associations - in other words, on word representation. Therefore language makes recollection possible and, consequently, allows reasoning about and real knowledge of objects. This link proposed by Freud between language and consciousness in these early texts is maintained throughout his work.
\end{abstract}

Key -words: Psychoanalysis; Freud; Representation; Language; Thought; Consciousness.

No texto de 1891, Sobre a concepção das afasias, Freud analisa um conjunto de hipóteses vigentes na neurologia da época - principalmente as hipóteses localizacionistas - sobre os distúrbios afásicos e o funcionamento da linguagem e, a partir da recusa de algumas dessas hipóteses e das conclusões a que chega, elabora uma nova concepção sobre a estrutura e o funcionamento do que ele chama "aparelho de linguagem". Como a teoria sobre o fun-

\footnotetext{
${ }^{1}$ Artigo recebido para publicação em 05/2001; aceito em 09/2001 ' Endereço para correspondência: Fátima Caropreso, Programa de PósGraduação em Filosofia e Metodologia das Ciências, UFSCar, Alameda das Orquídeas 550, Cidade Jardim, São Carlos, SP, CEP 13566-520. Email fatimacaropreso@uol.com.br
}

cionamento e a estrutura do sistema nervoso que embasava a teoria localizacionista das afasias subentendia uma concepção específica de representação, sua crítica resultará numa reformulação dessa noção. Neste texto, Freud propõe os conceitos de "representação de palavra" e "representação de objeto", os quais serão retomados no Projeto de uma psicologia, onde, entre outras coisas, ele tenta formular uma teoria do pensamento, em que a consciência do mesmo depende das associações lingüísticas que constituem a representação de palavra. $\mathrm{O}$ objetivo deste trabalho é analisar a relação estabelecida por Freud entre o pensamento, a linguagem e a consciência nestes seus dois textos iniciais. 
O conceito de "representação de palavra" e "representação de objeto" em "Sobre a concepção das afasias".

Em Sobre a concepção das afasias, Freud propõe que a palavra, que, do ponto de vista psicológi$\mathrm{co}$, é a unidade funcional da linguagem, é um complexo constituído por um intrincado processo de associações, no qual estão presentes quatro elementos: a "imagem acústica", a "imagem visual da letra", a "imagem cinestésica da falạ" ou "imagem glossocinestésica" e a "imagem cinestésica da escrita" ou "imagem quirocinestésica". O primeiro passo na aprendizagem da fala, ou seja, na constituição da representação de palavra, consiste em associar a imagem acústica, resultante da fala de outra pessoa, a uma imagem cinestésica, resultante da nossa própria fala. ${ }^{3}$ Quando o sujeito fala, surge uma segunda imagem acústica, decorrente do som pronunciado, que se associa às duas impressões anteriores. Nessa fase inicial da linguagem, as palavras produzidas não são idênticas às pronunciadas pelos outros, fazendo com que se empregue uma linguagem própria, decorrente da associação de diversos sons de palavras ouvidas com sons que o sujeito mesmo produz. A fala seria, então, aperfeiçoada através de uma tentativa de aproximar e fazer coincidir essas duas imagens acústicas. A imagem visual da palavra e a imagem cinestésica da escrita são acrescentadas ao complexo associativo, posteriormente, com a aprendizagem da leitura e da escrita. Na aquisição da linguagem, cada novo elemento que é acrescentado ao complexo associativo provoca uma reorganização das associações que o compõem, pois a aprendizagem, segundo o que Freud propõe, se dá por um processo de "sobreassociação". Com isso, ele quer dizer que a associação não é um processo mecânico, pois cada nova associação que se estabelece modifica a significação funcional das conexões anteriormente constituídas. Por exemplo, se há uma associação entre a imagem acústica e a imagem cinestésica de uma pa-

\footnotetext{
${ }^{3}$ Quando Freud fala que uma imagem se associa 2 uma outra imagem, por exemplo, que uma imagem acústica se associa a uma imagem cinestésica, deve-se entender que é um complexo de imagens acústicas que se associa a um complexo de imagens cinestésicas. Em uma passagem do Projeto de uma psicologia cientifica (p.41), ele deixa claro isto ao afirmar que as ocupaçōes (Besetzungen) perceptivas nunca são ocupações de neurônios isolados, mas sempre de complexos neuroniais
}

lavra, e esta ainda não foi vinculada a uma representação de objeto, tal associação exerce inicialmente a função de possibilitar a repetição de palavras ouvidas. Quando a imagem acústica da palavra associase à imagem visual de uma representação de objeto, aquela associação primária entre a imagem acústica e a imagem cinestésica da representação de palavra adquire um novo significado, pois passa a estar envolvida também na fala espontânea e significativa. Para Freud, a noção de sobreassociação expressa como as diferentes atividades da linguagem são efetuadas por meio das mesmas associações mediante as quais a aprendemos inicialmente, embora seja possível empregar abreviações e substituições. Todas as imagens sensoriais associam-se à imagem acústica, o que faz com que quase todas as atividades lingüísticas dependam dela. Além disso, é a partir da imagem acústica que a representação de palavra associa-se à representação de objeto, adquirindo assim um significado. Portanto, a imagem acústica é o elemento central na organizaçăo da representação de palavra.

A representação de objeto é também um complexo associativo constituído por imagens sensoriais, mas não apenas por imagens acústicas, visuais e cinestésicas, como a representação de palavra. Além de poder ser constituída por uma variedade maior de elementos sensoriais, a possibilidade de novos elementos se acrescentarem à representação de objeto nunca cessa, ao contrário da representação de palavra. Uma vez que as imagens acústicas, visuais e cinestésicas de uma determinada palavra se constituem, não há novos elementos a serem acrescentados àquela representação. Novas representações de palavras podem se constituir e se associar às anteriores, mas percepções diferentes da mesma palavra não alteram a estrutura da representação. Com relação à representação de um objeto específico, sempre há a possibilidades de que, por exemplo, percepções visuais de diferentes ângulos ou percepções tácteis de diferentes partes do mesmo sejam experienciadas $\mathrm{e}$, assim, acrescentem novos elementos à sua representação. Portanto, enquanto a representação de palavra é um complexo fechado, a representação de objeto constituiria um complexo aberto, no sentido de que sempre fica em aberto a possibilidade de que novos elementos se acrescentem aos anteriores. 
Esta concepção de objeto proposta por Freud provém, em parte, da concepção de objeto de Stuart Mill. Segundo este, quando dois fenômenos, que nunca foram experienciados ou pensados separados um do outro, são experienciados juntos com muita freqüência, produz-se entre eles uma "associação inseparável", que torna impossivel pensar os dois fenômenos separadamente, a não ser que alguma experiência subseqüente venha a dissolver a associação. De tal associação inseparável e da "capacidade de expectativa" da mente humana, resulta a idéia de um objeto externo, segundo Mill. A idéia de um mundo exterior a nós provém do fato de que, ao experienciarmos um conjunto de sensações associadas e que nos parecem inseparáveis, devido à nossa capacidade de expectativa - ou seja, a capacidade que possuímos de, após ter sensações reais, formar a concepção de sensações possíveis -, passamos a considerar que tais sensações sempre poderão ser experienciadas, por nós e por outros, em determinadas circunstâncias e que outras sensações desconhecidas possam ser acrescentadas às demais. De acordo com Mill, essa concepção de "sensaçōes possíveis" possui um caráter de permanência que se opõe ao caráter efêmero das nossas sensações e, a partir dessa diferenciação, somos levados a considerar que ambas são coisas diferentes, que as possibilidades de sensações existem independentes de nós, ou seja, que existem objetos exteriores. Ao expor sua concepção de objeto, Freud (1891/ 1973) menciona esta idéia de Stuart Mill. Ele diz:

"A idéia, ou conceito, de objeto é ela mesma outro complexo de associações composto pelas mais diversas impressões visuais, acústicas, cinestésicas e outras. Segundo o ensinamento da filosofia, a idéia de objeto não contém outra coisa; a aparência de uma "coisa", cujas "propriedades" nos são transmitidas por nossos sentidos, se origina somente do fato de que ao enumerar as impressões sensoriais percebidas de um objeto deixamos aberta a possibilidade de que se acrescente uma grande série de novas impressões à cadeia de associações (Mill, 1865/1974, p. 90)".

Tanto para Freud como para Mill, a idéia de objeto consiste num agregado de impressões sensoriais e, portanto, nossa idéia de uma coisa no mundo só pode ser uma inferência, ou uma "crença", que se origina a partir deste agregado de impressões e da nossa capacidade de conceber que essas sensações podem ser novamente experienciadas e que outras venham a ser experienciadas em associação com as anteriores.

Resumindo, a representação de palavra é um complexo associativo fechado que, pelo menos no caso dos substantivos, adquire significado a partir da sua associação com uma representação de objeto. Mas como a representação de objeto adquire significado? Em Sobre a concepção das afasias, Freud não se detêm sobre esse ponto, mas no Projeto de uma Psicologia científica ele afirma que para compreendermos uma representação perceptiva é necessário rastreá-la até uma sensação corporal Neste texto, Freud propõe que, inicialmente, o processo de juízo, ou de reconhecimento dos objetos, consiste numa tentativa de rastrear as percepções até ocupações ${ }^{4}$ oriundas do próprio corpo, ou seja, consiste numa tentativa de encontrar um caminho que leve das representações de objetos, que se constituem na parte do sistema de memória que recebe as ocupações perceptivas (y do manto), até as representações de experiências corporais, que se constituem na parte do sistema de memória que está em contato direto com o interior do organismo (y do núcleo). Citando Freud (1895/1995, p. 47):

"O julgar, mais tarde um meio para reconhecer o objeto que talvez tenha importância prática, é, assim, originariamente um processo associativo entre ocupações vindas do exterior e ocupações provindas do próprio corpo, uma identificação entre notícias ou ocupações de f e de dentro."

Por que o reconhecimento de um objeto depende de sua associação com uma experiência corporal? Uma vez que é a necessidade de se livrar do desprazer - ou seja, de fazer cessar a excitação proveniente do interior do corpo que incide sobre o sistema y do núcleo - que leva o sujeito a atentar para

\footnotetext{
"Estamos utilizando "ocupaçāo" para traduzir a "Besetzung" freudiana, usualmente vertida como "investimento", por esta funcionar melhor nesses textos que manejam um vocabulário ainda próximó do da neurologia.
} 


\section{Fátima Caropreso}

as ocupações perceptivas, todos os objetos serão inicialmente separados em dois grupos: os "objetos de desejo", que são associados com a eliminação do desprazer, e os "objetos hostis", que são associados com o aumento do desprazer. Portanto, originariamente, são as sensações corporais de prazer e desprazer que atribuem significado aos objetos, porque é a necessidade de se livrar do desprazer que leva o sujeito a atentar para as percepções.

Então, a representação de objeto adquire significado a partir da sua associação com sensações corporais e a representação de palavra, a partir da sua associação com a representação de objeto. Em última instância, portanto, as palavras referem-se sempre a sensações corporais. Em uma passagem dos Estudos sobre a histeria (Freud, 1895/1999), Freud explicita esta relação, ao discutir o papel da linguagem na sintomatologia histérica (Gabbi, 1995, p. 168):

"Todas essas sensações e inervações pertencem à "expressão das emoções", que, como Darwin [1872] nos ensinou, consiste em desempenhos originariamente significativos $e$ apropriados; por mais que hoje se encontrem, na maioria dos casos, debilitadas a tal ponto que sua expressão lingüística nos parece uma transcrição figurativa, é muito provável que tudo isto, antigamente, fosse entendido literalmente. A histeria acerta quando restabelece para suas inervações mais intensas o sentido originário da palavra."

Como tais idéias são retomadas no Projeto...? Pode-se dizer que, neste texto, Freud procura contextualizar o processo de aquisição da linguagem, descrito em Sobre a concepção das afasias, e explicitar a sua relação com os demais processos psíquicos.

\section{O papel da linguagem no "Projeto de uma psico- logia".}

No Projeto..., Freud desenvolve uma teoria em torno da noção de aparelho neuronial, a partir da qual tenta explicar os processos psíquicos normais $\mathrm{e}$ patológicos. Este aparelho é pensado a partir de dois postulados principais: o "neurônio", que é conside- rado a unidade material do aparelho, e a "quantidade" (Q), que é definida como algo que diferencia a atividade do repouso e que está submetida à lei geral do movimento. Freud não especifica, ao longo de toda a sua obra, qual é a natureza da quantidade, apesar de deixar claro quais são suas características essenciais. No artigo As neuropsicoses de defesa (Freud,1894/1999, p. 61), arfimara que:

"Nas funções psíquicas cabe distinguir algo (cota de afeto, soma de excitação) que tem todas as propriedades de uma quantidade - embora não tenhamos meio de medi-la; algo que é suscetivel de aumento e diminuição, deslocamento e descarga, $e$ se difunde pelos traços mnêmicos das representações como o faria uma carga elétrica pela superficie dos corpos."

Strachey (1999), em seu apêndice sobre a natureza da quantidade, comenta que, embora Freud no artigo As neuropsicoses de defesa tenha feito uma vaga comparação entre uma coisa que era precursora da quantidade e "uma carga elétrica espalhada pela superfície de um corpo" e nos Estudos sobre a histeria (Freud, 1895/1999) tenha dedicado um espaço a uma analogia entre a quota de afeto e uma certa medida de excitação elétrica nas vias condutoras do encéfalo, não há nenhuma palavra no Projeto... que possa ser interpretada no sentido de que Freud entendesse a quantidade estritamente dessa forma. Pribram e Gill (1976) discordam dessa interpretação, pois consideram que há, no Projeto..., uma definição biológica do conceito de energia, que pode ser significativamente ligada à neurofisiologia moderna. Segundo eles, a noção de quantidade refere-se às quantidades físicas e químicas da excitação cerebral.

O aparelho neuronial possuiria, desde sua origem, uma tendência a manter o nível de quantidade o mais baixo possivel, tendência esta que pode ser entendida, pelo fato de Freud ter identificado o aumento da quantidade com o desprazer e a sua diminuição com o prazer, como uma tendência a evitar o desprazer. Freud deixa claro que seu objetivo é explicar todos os processos psíquicos mecanicamente, mas que, quando tais explicações não forem suficientes, deve-se recorrer a justificativas biológicas, ou seja, buscar explicar algumas características dos pro- 
cessos como sendo aquisições biológicas condicionadas pelo evitar do desprazer.

Três sistemas de neurônios compõem o aparetho neuronial. Esses sistemas são diferentes uns dos outros, não devido à natureza dos neurônios que o compõem, pois todos são, por hipótese, estruturalmente idênticos, mas devido ao modo de ação da quantidade. Há um sistema para a recepção de estímulos exógenos, o sistema f; um sistema que registra as informações recebidas, ou seja, um sistema representacional ou de memória, o sistema y; e um sistema responsável pela consciência, o sistema w. Entre os neurônios, há "barreiras de contato", que resistem à passagem da quantidade. $\mathrm{O}$ sistema $\mathrm{f}$ recebe quantidades cujas intensidades são muito superiores à capacidade de resistência das barreiras de contato; portanto, nesse sistema, a quantidade não encontra resistência à sua passagem. No sistema y, como as quantidades que o atingem são menos intensas, as barreiras de contato podem resistir à passagem da quantidade, o que faz com que seja necessário que dois neurônios ocupados simultaneamente pressionem uma mesma barreira de contato e, assim, superem a resistência oferecida por ela, possibilitando a passagem da quantidade. Quando esta supera a resistência de uma barreira de contato, tal barreira é "facilitada" (isto é, tornada mais permeável) e, numa segunda ocupação do neurônio, a resistência encontrada será menor, o que fará com que a excitação tenda a percorrer o mesmo caminho percorrido na primeira vez. Portanto, estas facilitações constituem caminhos preferenciais diferenciados no sistema y, que possibilitam a memória. Podemos considerar, de acordo com a teoria apresentada em Sobre a concepção das afasias, que os elementos que são associados na constituição dos correlatos neurológicos da representação são os neurônios de que Freud fala aqui no Projeto... e que a associação consiste na passagem da quantidade de um neurônio para outro, a qual estabelece uma facilitação entre eles, tornando-os ligados. ${ }^{5}$

Como o aparelho não recebe apenas quantidade exógena, mas também quantidade endógena, o

\footnotetext{
'Só que no Projeto... este processo quantitativo é a própria representação e não um correlato da representação, como Freud propôs em Sobre a concepçāo das afasias. Os processos representacionais no Projeto... não são processos conscientes, mas a consciência pode vir a acrescentarse a eles em algumas situações. No texto sobre as afasias, ao contrário, a representação parece implicar, por si só, a consciência.
}

sistema y é diferenciado em "y do manto" e "y do núcleo". No primeiro, formam-se as representações resultantes dos estímulos externos e, no segundo, as representações resultantes dos estímulos oriundos do interior do corpo. A quantidade externa que atinge $f$ é, em parte, descarregada pela via motora e, em parte, conduzida à y do manto, onde dá origem às representações. A consciência de uma representação depende de "signos de qualidade", que são fornecidos por w diante de ocupações perceptivas. A qualidade é considerada como resultante de uma propriedade da quantidade, o período, isto é: a frequiência ou as propriedades temporais da estimulação. As afirmações de Freud sobre como a qualidade surge a partir da quantidade são bastante ambíguas e este é um dos principais pontos obscuros do Projeto...

Os estímulos exógenos podem ser descarregados através de movimentos reflexos, que, em princípio, permitiriam também a fuga de estímulo, isto é, colocariam o organismo fora do alcance da fonte de estimulação externa, cumprindo o que Freud denomina "função secundária" (a função primária seria apenas a descarga da quantidade). Os estímulos endógenos, no entanto, só são suprimidos plenamente com a execução de uma "ação específica" sobre o mundo, ou seja, sua supressão depende da obtenção de um objeto específico - por exemplo, alimento, no caso da fome - e, para essa obtenção, é necessário operar uma modificação sobre o meio externo. Para a execução desta ação, é necessário haver um armazenamento de quantidade no aparelho e, além disso, é necessário haver um aprendizado de tais ações, que depende da memória. Dessas duas necessidades decorrem todos os processos psíquicos mais complexos, como veremos. Como y do núcleo está em contato com os estímulos provenientes do interior do corpo, ocorre aí um acúmulo de quantidade que faz com que o aparelho possua uma quantidade armazenada para ser utilizada no direcionamento dos processos associativos. Estes neurônios de y do núcleo constantemente ocupado são definidos como constituindo o "eu". Este pode interferir em todas as ocupações de y do manto, portanto, é constituído por uma parte constante, que consiste no núcleo de y, e por uma parte variável, que consiste nas ocupações ocasionais de y do manto, as quais são chamadas por Freud de "ocupações variáveis". Essas ,ocupações 
variáveis possuem a função de inibir os processos que seguem apenas as facilitaçōes estabelecidas processos estes que são chamados de "processos primários" -, de modo a possibilitar a aprendizagem de respostas adequadas por parte do sujeito, instituindo assim, no lugar dos processos associativos primários, os "processos secundários".

Mas que papel a linguagem desempenhará neste aparelho? As associações lingüísticas, ou seja, as associações que constituem as representações de palavras, são introduzidas por Freud, na terceira parte do Projeto..., para explicar como as ocupações variáveis do eu que constituem o pensamento podem se tornar conscientes. De acordo com a teoria do Projeto..., a representação de palavra começa a se formar no momento que antecede o que Freud chamou de "vivência de satisfação". Quando o bebê sente fome pela primeira vez - ou seja, quando os estímulos endógenos pela primeira vez conseguem superar a resistência das barreiras de contato que separam y do núcleo do interior do organismo -, o aumento da excitação em y do núcleo conduz à descargas reflexas, pois estas consistem no único meio de eliminação da quantidade que o bebê possui. Entre estas eliminações reflexas está o grito que, inicialmente, consiste apenas numa forma de descarga, mas que adquire uma função secundária de "comunicação", a partir do momento em que passa a funcionar como um meio para o indivíduo necessitado comunicar seu estado à outra pessoa:

"A inervação lingüística é originariamente uma via de eliminação que age como um tipo de válvula para y, a fim de regular as oscilações de $Q$ 'n, um fragmento da via para alteração interna, que apresenta a única eliminação enquanto a ação específica não for encontrada. Essa via ganha uma função secundária, na medida em que chama a atenção do indivíduo prestativo (geralmente o próprio objeto de desejo) para o estado de apetite e necessitado da criança, e serve a partir daí à compreensão...". (Freud, 1950/1995, p.80)

Para Freud, o grito assinala a origem da linguagem - ou seja, a partir dele se originam as primeiras imagens acústicas e imagens cinestésicas que vão constituir a representação de palavra. A constituição das associações lingüísticas, além de dotar a criança de um meio para a comunicação do seu estado, possibilita a rememoração, ou seja, possibilita que as representações ocupadas pelo eu despertem signos de qualidade e, assim, se tornem conscientes. Vejamos como isso se dá.

A consciência, como foi dito anteriormente, depende de signos de qualidade que são fornecidos pelo sistema w diante de percepções, ou seja, diante de ocupações provenientes de $f$ e de inervações motoras. Então, para que uma representação ocupada pelo eu se torne consciente, é necessário obter, a partir da sua ocupação, uma percepção:

"...signos de qualidade normalmente vêm apenas de P; portanto, se trata de obter, a partir do curso de Q'n, uma percepção. Se estivesse ligado ao curso de $Q$ 'n uma eliminação (junto com a circulação), esta forneceria, como todo movimento, uma noticia de movimento". (Freud, 1950/1895, p. 79)

Um dos componentes da representação de palavra - a imagem cinestésica - é que possibilita isto. Quando a ocupação da representação de objeto segue para a imagem acústica da representação de palavra e, desta, para a imagem cinestésica, um signo de qualidade é fornecido, ou seja, obtêm-se uma percepção do curso associativo, pois as imagens de movimento produzem percepções e, então, os processos que ocorrem em y como resultado da ação do eu podem se tornar conscientes, surgindo, com isso, a possibilidade de sua rememoração:

“...se as imagens de recordação forem tais que uma corrente parcial possa ir de uma delas para as imagens acústicas e para as imagens motoras da palavra, a ocupação das imagens de recordação é acompanhada de notícias de eliminação, os signos de qualidade, com isso, são também signos de cons[ciência] da re[cordação]". (Freud, 1950/1895, p.79)

Portanto, enquanto houver apenas representações de objetos em y, os processos que aí ocorrem - com exceção dos que consistem em inervações motoras e em alucinações - serão inconscientes; e esta forma de consciência é "imediata", ou seja, ela decorre única e diretamente das propriedades das percepções. Com a linguagem, surge uma segunda forma 
de consciência, uma consciência "mediata", isto é, intermediada pelos signos lingüísticos. Antes da constituição das associações lingüísticas, a consciência só pode resultar de percepções externas e de movimentos $^{6} \mathrm{e}$, então, nesse período, só é possível pensamento consciente se este consistir em uma ação. Desta forma, antes das associações lingüísticas, o pensamento consciente não se diferencia inteiramente da ação. Mas em que consiste o pensamento para Freud?

O pensamento deriva da vivência de satisfação, que tem como modelo a satisfação da fome. Na fome, quando uma pessoa percebe a insatisfação da criança e realiza a ação específica - por exemplo, quando a mãe coloca a criança para mamar - esta, através de ações reflexas, realiza os movimentos necessários para a alimentação e, assim, a recepção dos estímulos endógenos cai abaixo do nível da resistência das barreiras de contato de y do núcleo. $\mathrm{O}$ fim dessa excitação que produz desprazer é o que Freud chama de "vivência de satisfação". Como consequiência de tal vivência ocorrem três coisas em y. Em primeiro lugar, a excitação endógena que gerava desprazer cessa; em segundo lugar, constitui-se uma representação do objeto externo, cuja percepção foi simultânea à experiência de satisfação; e, em terceiro, forma-se uma representação do movimento reflexo executado, que proporcionou a satisfação. Entre essas duas representações de y do manto e a representação do estado de carência em y do núcleo se estabelece uma facilitação, devido ao fato de que as primeiras constituem-se simultaneamente à desocupação da segunda. Uma vez estabelecidas tais facilitações, quando o estado de excitação reaparece, o processo excitatório segue o caminho constituído por elas e ocupa as representações em y do manto. ${ }^{7}$ Nesse caso, não havendo nenhuma espécie de inibição,

\footnotetext{
' $\mathrm{O}$ único caso em que é possível que um processo do eu torne-se consciente, antes da constituição das associações lingüísticas, sem que consista em ocupaçōes de imagens de movimento, é a alucinação. $\mathrm{Na}$ alucinaçăo há uma ocupação muito intensa das representaçōes de y do manto em retrogradação, ou seja, que vai de y para f e, deste, para w e acaba despertando signos de qualidade, já que-provoca os mesmos efeitos de uma percepção externa.

' Esta tendência para investir as representaçōes de y do manto é o que Freud chama de "desejo". O desejo é uma tendência para investir a representação de um objeto, e a ocupação desta representação consiste em uma "realização de desejo". Na segunda ocorrência do processo, não há apenas uma necessidade, mas já há um desejo, pois o estado de carência já se associou à representação de um objeto e, agora, visa especificamente sua ocupação.
}

a ocupação da representação do objeto devido à animação de desejo possui a mesma intensidade de uma percepção e, por isso, resulta em uma alucinação. Em conseqüência dessa alucinação, a ação reflexa é executada e, nessas condições, resulta em frustração; o desprazer continua, porque a fonte interna de estimulação não é anulada. Portanto, para que o indivíduo sobreviva, é necessário haver uma alteração nessa tendência primária do processo associativo, que permita ao eu diferenciar entre uma rememoração e uma percepção e que permita a ele aprender a executar as ações específicas que possibilitam a satisfação da necessidade.

Como, na repetição da vivência de satisfação, a ocupação muito intensa da representação desejada e das imagens motoras a ela associadas provoca uma intensificação do desprazer, a tendência do aparelho a não ocupar representações que conduzem à liberação de desprazer - ou seja, a “defesa primária”, que é considerada por Freud a "primeira regra biológica" que dirige os processos associativos -, faz com que o eu, primeiro, não ocupe mais todas as representações de movimento constituídas na vivência de satisfação e, depois, não ocupe mais a representação de desejo tão intensamente. Com isto, os sinais de qualidade não são mais fornecidos na ausência do objeto na realidade e, então, quando surge um signo de qualidade, este pode funcionar como um "signo de realidade", que possibilita ao sujeito discriminar entre uma representação rememorada e uma representação percebida. A partir disto, o eu aprende que é necessário permanecer atento aos signos de qualidade resultantes das percepções, pois só assim a satisfação real pode ser obtida. Surge, então, o mecanismo da "atenção", que, segundo Freud, consiste na "segunda regra biológica" que dirige os processos associativos, ou seja, surge uma atenção prévia aos signos de qualidade. Tais signos permanecem ocupados pelo eu e, quando são ocupados a partir de w, ou seja, quando são "sobreocupados", as facilitações existentes entre eles e as ocupações perceptivas conduzem a ocupação para as últimas. Então, para que os estímulos externos sejam percebidos, é necessário não apenas que tais estímulos alcancem y, mas que as representações constituídas por eles sejam também ocupadas pelo eu. Por isso, Freud afirma que: "o juízo sobre as propriedades quantitati- 


\section{Fátima Caropreso}

vas dos objetos não é alterado em princípio pela atenção" (Freud, 1950/1995, p.77). Conseqüentemente, a quantidade externa dos objetos não pode expressar-se em y por quantidade psíquica. Só quando o juízo sobre as propriedades quantitativas dos objetos passa a ser alterado pela atenção, ou seja, quando as ocupações perceptivas são ocupadas também pelo eu, a Q externa pode ser expressa por Q psíquica. Esta explicação sobre o mecanismo da atenção deixa clara a relação entre a memória e a consciência. Das representações que se formam, apenas aquelas cujos signos de qualidade são focalizados pela atenção se tornam conscientes. Portanto, a consciência é posterior à memória e restrita em relação a ela. A partir do momento em que surge o mecanismo da atenção, novas representações de palavras se constituem, à medida que os complexos perceptivos vão se associando a imagens acústicas provenientes da fala alheia.

Com a inibição do processo primário, ocorre um acúmulo de quantidade no eu que permite a ele direcionar os processos associativos de modo que estes conduzam à satisfação. A partir de então, a ocupação dos neurônios de y do núcleo conduz a uma ocupação pouco intensa da representação de desejo, de forma que esta é apenas rememorada sem ser alucinada ${ }^{8}$. Através de uma comparação entre tal representação e as representações provenientes da percepção - processo este que é chamado por Freud de "juízo"- o sujeito passa a discriminar, nos complexos perceptivos, uma parte que coincide com as representações de desejo e uma parte que não coincide $^{9}$ e, a partir da parte discordante do complexo, tenta encontrar um caminho que leve à representa-

\footnotetext{
${ }^{8}$ Uma vez que a rememoração de uma representação depende da sua associação com representações de palavras, é necessário que a representação de desejo esteja associada a uma representação de palavra, para que ela possa ser rememorada. Embora Freud não explicite isto, possível supor que é a associação com as imagens acústicas e cinestésicas do grito, que permitem a rememoração da representação de desejo. No momento que antecede a vivência de satisfação, as representações do grito e das demais eliminações reflexas estão ocupadas e, quando a ação específica é executada, a ocupação segue destas representações correspondentes às eliminações para as representaçōes que constituem a vivência de satisfação, estabelecendo-se, assim, uma associação entre a representação do objeto de desejo e o grito. Esta associação tomaria possível a rememoração da representação de desejo.

${ }_{9}^{9}$ Nos casos em que o complexo perceptivo não coincide em nada com o desejado, o eu segue as facilitações da representação perceptiva e tenta, a partir dela, encontrar uma representação que coincida parcialmente com a desejada e que esteja associada a ela.
}

ção desejada, ou seja, que leve à coincidência total e, então, permita a satisfação. Esses processos que transcorrem entre o surgimento do desejo e sua satisfação constituem o pensamento para Freud. Originariamente, o pensamento tem como meta a obtenção da identidade entre a representação mnêmica correspondente ao objeto de desejo e a percepção seguida de eliminação motora; constitui, portanto, um caminho para a realização de desejo. Posteriormente, ele se torna independente desta meta e passa a visar apenas o reconhecimento dos objetos. Esta forma secundária de pensamento desdobra-se a partir da primária e, embora deixe de seguir exclusivamente a meta de realização de desejo, continua contribuindo para esta, pois permite o reconhecimento dos objetos e de suas relações com o objeto desejado, o que facilita a busca de um caminho que conduza à ação específica.

Segundo Freud, este caminho percorrido pelo pensamento consiste, inicialmente, na reanimação de uma ação decorrente do lado acidental da ação específica. Desse modo, a reocupação das imagens de movimento constitui o pensamento em seu momento inicial. Portanto, nesse momento, pensamento e ação não se diferenciam:

“...se o neurônio a coincidir, mas for percebido neurônioc no lugar de neurônio b, o trabalho do eu segue as ligações desse neurônio c e faz surgir, por meio da corrente de Q'n ao longo dessas ligações, novas ocupações até encontrar acesso para o neurônio faltante $b$. Em geral, resulta em uma imagem de movimento, que se intercala entre neurônio $c e$ neurônio $b$, e com a reanimação desta imagem, por um movimento efetivamente reali$z a d o$, é produzida a percepção do neurônio $b$ $e$, com isso, a identidade procurada. Por exemplo, seja a imagem recordativa desejada a imagem do busto materno e seu mamilo em visão completa, e a primeira percepção uma visão lateral deste objeto sem o mamilo. $\mathrm{Na}$ recordação da criança encontra-se uma experiência ocorrida por acaso na amamentação, onde um determinado movimento de cabeça transformou a imagem completa em lateral. A imagem lateral vista con- 
duz agora a um movimento de cabeça que uma tentativa mostra-, tem de ser executado ao contrário, e chega se à percepção da visão completa" (Freud, 1950/1995, p. 42)

Posteriormente, o pensamento passa a ser executado com quantidades menores e, então, pode ser diferenciado da ação pela intensidade do processo. Como afirma Freud (1895/1995, p. 82): “o representar e o mover são apenas quantitativamente distintos". Não é explicado como, a partir de um certo momento, é possível pensar sem se mover, mas é possível supor que o que possibilita esta distinção é a constituição das associações lingüísticas, pois elas permitem a rememoração das percepções, ou seja, permitem que as ações sejam rememoradas sem serem executadas. A partir de então, não é mais necessário agir para pensar, a ação pode ser imaginada, surge a capacidade de raciocínio. Com isso, o pensamento pode ocorrer na ausência da necessidade real, de forma que antecipe os possíveis caminhos que conduzem à satisfação, o que permite que esta seja obtida mais rapidamente quando o desejo, de fato, surgir. Pode-se dizer que as imagens cinestésicas da palavra substituem a ação e que, portanto, a linguagem permite que o pensamento se diferencie desta.

Então, a partir do momento em que surge o mecanismo da atenção e o eu passa a julgar os complexos perceptivos, ou seja, a partir do momento que o eu tenta identificá-los a representações já conhecidas, as representações de palavras vão se constituindo, pois os sons fazem parte dos complexos perceptivos e, devido à tendência à imitação presente no juízo, o sujeito tenta encontrar imagens cinestésicas que produzam imagens acústicas semelhantes às provenientes dos sons pronunciados por outros:

"Ora, não é preciso muito para inventar-se a linguagem. Há outros objetos que produzem constantemente certas fonias; portanto, um som desempenha um papel em seu complexo perceptivo. Em virtude da tendência de imitação, presente no julgar, pode encontrar-se para esta imagem sonora a noticia de movimento. Também esta classe de recordações pode tornar-se agora consciente. Todavia res- ta ainda associar sons deliberados com as percepções, então as recordações, através da atenção aos signos descarga sonora, tornamse conscientes como as percepções e podem ser ocupadas a partir de y". (Freud, 1950/ 1995 , p. 81)

Desta forma, cada vez mais representações de objeto podem ser rememoradas até que a linguagem adquira a capacidade de substituir completamente a ação. Podemos supor que, com esta tentativa, presente no juízo, de identificar as percepções externas a representações já conhecidas, ou seja, a representações que já possuem um significado que é dado pela sua associação com representações de y do núcleo por meio da representação de desejo, os objetos vão adquirindo significados, assim como as palavras a eles associadas. Então, a busca da satisfação, que é a finalidade do juízo, acaba por conduzir à compreensão do mundo externo.

Este pensamento discutido anteriormente que tem como meta a obtenção da identidade entre percepção e representação de desejo é chamado por Freud de "pensamento prático" ou "pensamento reprodutivo". A linguagem, além de tornar tal pensamento mais eficiente da forma como descrevemos anteriormente, permite ainda que o pensamento abandone essa sua meta prática e busque apenas o reconhecimento dos objetos. Esta forma de pensamento é chamada por Freud de "pensamento teórico" ou "pensamento recognitivo". No pensamento prático, o objetivo é encontrar um caminho que conduza à representação de desejo; nele, as representações que produzem desprazer são evitadas, pois tais representações não fazem parte dos caminhos que levam à realização de desejo. No pensamento teórico, o reconhecimento dos objetos é alcançado através da ocupação de todas as vias associadas a um objeto, inclusive as que conduzem ao desprazer. Isto é possível porque a linguagem permite que as representações de palavras sejam ocupadas no lugar das representações de objetos hostis, de modo que tais representações sejam rememoradas sem que o desprazer seja evocado. Portanto, a linguagem permite um pensamento imparcial, permite uma forma elevada de pensamento, como afirma Freud (1895/1995, p. 88): "o pensar com ocupação dos signos de realidade do 


\section{Fátima Caropreso}

pensar ou signos lingüísticos é, portanto, a forma mais elevada, mais segura, do processo de pensar recognitivo". Para que tal pensamento seja possível, é necessário que o eu ocupe constantemente os signos de qualidade lingüísticos, pois só dessa forma o curso associativo não é influenciado pelas representações de desejo. Deste modo, o desejo distorce o conhecimento dos objetos, e permanecer atento aos signos de qualidade linguísticos é a única forma de evitar esta distorção. Portanto, só a linguagem permite o conhecimento real dos objetos, pois ela consiste na única via de acesso a representações desprazerosas.

\section{Conclusão}

Enquanto há apenas répresentações de objetos, os processo que ocorrem em y resultantes da ação do eu são inconscientes. A partir do momento em que surge a representação de palavra, as representações ocupadas pelo eu podem se tornar conscientes uma segunda forma de consciência, uma consciência mediata. Como consequiência disto, o pensar se torna independente do agir, ou seja, surge a capacidade de raciocínio. Além disso, com a linguagem, as representações associadas ao desprazer passam a ser acessíveis, o que torna o pensamento não só independente da ação, mas também independente do desejo. Portanto, a linguagem, para Freud, permite uma consciência mediata, que traz consigo a possibilidade de raciocínio e de conhecimento.

Este vínculo estabelecido por Freud entre a linguagem e a consciência no Projeto... permanece ao longo de toda a sua obra. Como aponta Forrester (1980/1983), embora tal idéia desapareça dos textos de Freud durante a primeira década de 1900, ela reaparece nos "trabalhos sobre metapsicologia", de 1915, da mesma forma como foi formulada inicialmente.

\section{Referências bibliográficas:}

Forrester, J. (1983). A linguagem e as origens da psicanálise. (E.P. Moura, Trad.) Rio de Janeiro: Imago. (Originalmente publicado em 1980)

Freud, S. (1973). La Afasia. (R. Alcade, Trad.) Buenos Aires: Nueva Visión. (Originalmente publicado em 1891)

Freud, S. (1999). Las neuropsicosis de defensa. Em: Sigmund Freud Obras Completas, vol. III. Buenos Aires: Amorrortu Editores. (Originalmente publicado em 1894)

Freud, S. (1995). Projeto de uma psicologia. Rio de Janeiro: Imago. (Escrito em 1895 e publicado originalmente em 1950)

Freud, S. (1999). Estudios sobre la histeria. (J.L. Etcheverry, Trad.) Em: Sigmund Freud Obras Completas, vol.II. Buenos Aires: Amorrortu Editores. (Originalmente publicado em 1895)

Freud, S. (1999). La negación. (J.L. Etcheverry, Trad.) Em: Sigmund Freud Obras Completas, vol.XIX. Buenos Aires: Amorrortu Editores. (Originalmente publicado em 1925)

Gabbi, O.F. (1995). Notas críticas sobre "Entwurf einer Psychologie". Em: Projeto de uma Psicologia (pp. 103-225). Rio de Janeiro: Imago.

Mill, J. S. (1974). Um exame da filosofia de Sir William Hamilton. São Paulo: Abril Cultural. (Originalmente publicado em 1865)

Pribram, K. \& Gill, M. (sem data). $O$ "Projeto" de Freud: uma reavaliação. São Paulo: Cultrix. (Trabalho originalmente publicado em 1976)

Strachey, J.(1999). Apéndice C. La natureza de Q Em: Sigmund Freud Obras Completas, vol. I (pp.441-446). Buenos Aires: Amorrortu Editores.

Apoio FAPESP -Bolsa Mestrado 